\title{
Remifentanil injected during analepsia shortens length of postanesthesia care unit stay in patients undergoing laparoscopic surgery for endometrial cancer: a randomized controlled trial
}

\author{
Lin-Jia $\mathrm{Zhu}^{\wedge}$, Si-Bi Zhang, Xiu-Hong Jiang, Yan $\mathrm{Ni}^{\wedge}$ \\ Department of Anesthesiology and Perioperative Medicine, The First Affiliated Hospital with Nanjing Medical University, Nanjing, China \\ Contributions: (I) Conception and design: Y Ni; (II) Administrative support: XH Jiang; (III) Provision of study materials or patients: LJ Zhu; (IV) \\ Collection and assembly of data: SB Zhang; (V) Data analysis and interpretation: LJ Zhu, SB Zhang; (VI) Manuscript writing: All authors; (VII) Final \\ approval of manuscript: All authors. \\ Correspondence to: Yan Ni, MD. Department of Anesthesiology and Perioperative Medicine, The First Affiliated Hospital with Nanjing Medical \\ University, 300 Guangzhou Road, Nanjing 210029, China. Email: niyan812@njmu.edu.cn.
}

Background To guarantee efficient operating room (OR) activity, tracheal extubation is often performed
in the postanesthesia care unit (PACU). Therefore, the ability of PACU to accommodate postoperative
patients is crucial. Optimizing extubation management may speed up the turnover of PACU beds. The
aim of the present study was to investigate the effect of remifentanil, which is used during analepsia, on the
length of PACU stay in patients undergoing laparoscopic surgery for endometrial cancer. Methods: In this prospective trial, we recruited a total of 99 patients, who were scheduled for laparoscopic surgery for endometrial cancer. At the end of the surgery, all patients were immediately transferred to the PACU and continued mechanical ventilation. Upon PACU admission, sputum aspiration was routinely performed. If the hemodynamic parameters fluctuated $>30 \%$ of the baseline level, or patients moved unconsciously without reaching the criteria of extubation, a bolus injection of either $1 \mu \mathrm{g} / \mathrm{kg}$ remifentanil (Rem group, $\mathrm{n}=51$ ) or propofol $1.0 \mathrm{mg} / \mathrm{kg}$ (Pro group, $\mathrm{n}=48$ ) was randomly administered. The primary outcome was the duration of PACU stay. The secondary outcomes included time to respiratory breath recovery and time to extubation, along with bispectral index (BIS) values and hemodynamic status after remifentanil or propofol intervention. Times of repeated intervention, rescue administration of vasoactive drugs, and the incidence of adverse events were recorded. Visual analog scale and satisfaction scores at the time of PACU discharge were also evaluated.

Results: The duration of PACU stay was shorter in the Rem group than in the Pro group [49 minutes (46.47-51.06 minutes) vs. 62 minutes (60.75-69.29 minutes), $\mathrm{P}<0.0001]$. Compared with the Pro group, the time to spontaneous breathing recovery, the time to extubation, and the incidence of hypoxemia after extubation were reduced in the Rem group $(\mathrm{P}<0.0001, \mathrm{P}<0.0001, \mathrm{P}=0.03$, respectively). After anesthetic administration, the BIS value decreased less in the Rem group $(\mathrm{P}<0.0001)$; blood pressure and heart rate $(\mathrm{HR})$ declined, but were comparable in both groups.

Conclusions: Remifentanil, which is injected during analepsia, significantly shortens the duration of PACU stay without increasing adverse events in the peri-extubation period.

Keywords: Endotracheal extubation; postanesthesia care unit (PACU); propofol; remifentanil; hypoxemia

Submitted May 20, 2020. Accepted for publication Sep 03, 2020.

doi: 10.21037/apm-20-1146

View this article at: http://dx.doi.org/10.21037/apm-20-1146

\footnotetext{
^ Lin-Jia Zhu: ORCID: 0000-0002-6559-6162; Yan Ni: ORCID: 0000-0001-5228-2677
} 


\section{Introduction}

Laparoscopic procedures are the main surgical treatment for patients with endometrial cancer. A deep muscle relaxant is often required to maintain sufficient abdominal capacity at a low pneumoperitoneum pressure, consequently decreasing the side-effects of laparoscopy and leading to enhanced recovery after surgery (1). However, due to the short interval between the laparoscopic procedure and the last stitch, many patients may suffer from residual neuromuscular relaxation despite neuromuscular block monitoring. Therefore, to guarantee efficient operating room (OR) activity, tracheal extubation is often performed in the postanesthesia care unit (PACU). During the PACU stay, a rescue anesthetic, such as propofol, is often used for smooth extubation and to optimize emergence (2), which may prolong recovery time and result in PACU "stacking".

PACU, caring for patients after surgery and other procedures, is an integral component of the surgical care system. PACU and OR activity are closely linked: efficient surgical processes require timely access to the PACU and early transportation back to the ward (3). Therefore, safe and effective acceleration of PACU throughput is of utmost importance.

Propofol has been widely used for sedation in the PACU (4). However, due to its unpredictable interindividual variability in pharmacokinetics and pharmacodynamics, propofol may be associated with prolonged recovery time (5-7). Therefore, propofol may be not the most appropriate sedative anesthetic during extubation. Remifentanil, a rapidly effective and short-term opioid analgesic, has been used for sedation and analgesia for awake intubation (8). Remifentanil has been used for intensive care unit (ICU) patients because its analgesia-based sedation can provide effective sedation and rapid extubation without the need for propofol, especially in those with renal or liver dysfunction (9). In the present prospective clinical trial, we compared the effects of remifentanil and propofol use during emergence on the length of PACU stay for patients undergoing laparoscopic surgery for endometrial cancer. We present the following article in accordance with the CONSORT reporting checklist (available at http://dx.doi. org/10.21037/apm-20-1146).

\section{Methods}

\section{Basic patient data and characteristics}

The present study was a randomized controlled clinical trial. Approval was obtained from the Institutional Review Board of the First Affiliated Hospital of Nanjing Medical University (No.: 2019-SR-225), and the trial was registered in the Chinese Clinical Trial Registry (trial registration No. ChiCTR1900025773). The investigators randomly assigned the participants into the propofol or remifentanil group at a ratio of 1:1. Concealed randomization was performed using Random Allocation Software (Microsoft). Group identification was concealed in numbered envelopes. Participants were included and allocated in numerical order. The anesthetist in the PACU was responsible for the anesthetic intervention. Nursing staff responsible for collecting the data in the PACU were not informed of the intervention settings.

We recruited patients who were scheduled for laparoscopic staging of endometrial cancer under general anesthesia in our hospital. Written informed consent was obtained from all patients or their legal representative prior to enrollment in the study. The inclusion criteria were as follows: (I) age 18-64 years; (II) American Society of Anesthesiology Physical Status I or II; (III) body mass index $18-26 \mathrm{~kg} / \mathrm{m}^{2}$, and (IV) duration of surgery $>2$ hours. Patients with asthma, chronic obstructive pulmonary disease, snoring, neuromuscular diseases, alcohol or narcotic dependence, soybean allergy, and significant hemodynamic instability during surgery were excluded. Upon admission to the PACU, routine monitoring was performed, followed by sputum aspiration. A bolus injection of either $1 \mu \mathrm{g} / \mathrm{kg}$ remifentanil (Rem group) or $1 \mathrm{mg} / \mathrm{kg}$ propofol (Pro group) was randomly administered if the patients moved while unconscious, or if hemodynamic parameters fluctuated $>30 \%$ of the baseline level. Randomization was performed by computer-generated random number allocations that were concealed in an opaque envelope. The study was conducted in accordance with the Declaration of Helsinki (as revised in 2013).

\section{Anesthetic methods}

All patients routinely fasted before surgery without premedication. Upon arrival at the OR, electrocardiography, invasive blood pressure, heart rate (HR), respiratory rate (RR), end-tidal carbon dioxide, bispectral index (BIS), and peripheral arterial oxygen saturation $\left(\mathrm{SpO}_{2}\right)$ were routinely monitored using a Mindray T6 monitor. Before the surgery, bilateral transversus abdominis plane block was performed under ultrasound guidance for perioperative analgesia. Subsequently, standard general anesthesia was initiated 


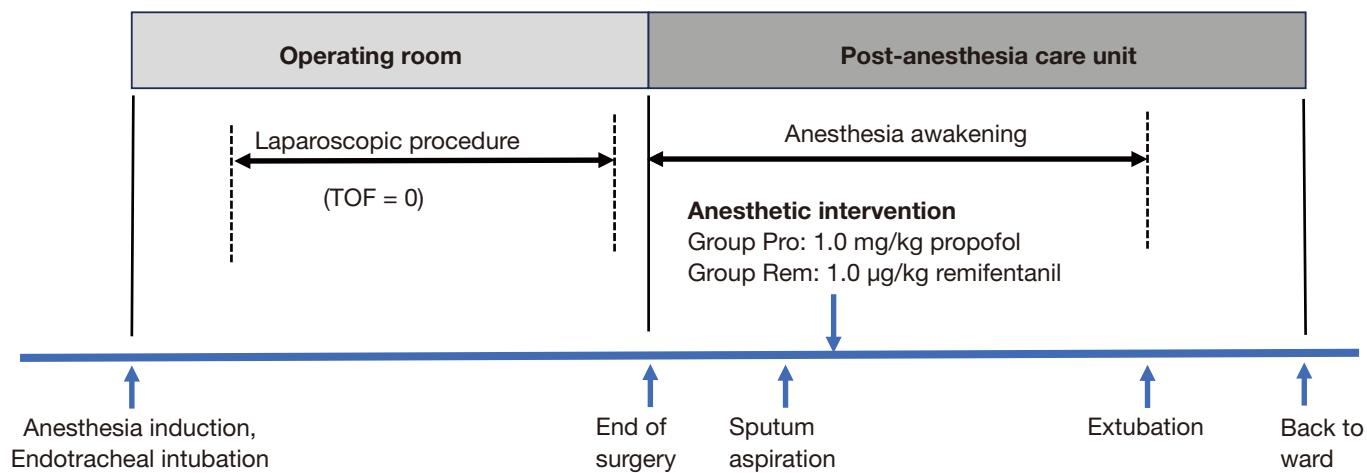

Figure 1 Study protocol. Upon admission to the postanesthesia care unit (PACU), sputum aspiration was performed, followed by a random bolus injection of either $1 \mu \mathrm{g} / \mathrm{kg}$ remifentanil (Rem group) or propofol (Pro group), as necessary. Tracheal tube was withdrawn according to the standard indication of extubation. Duration of PACU stay was defined as the interval from PACU admission to modified Aldrete score $\geq 9$. Rem, remifentanil; Pro, propofol.

by the administration of $0.05 \mathrm{mg} / \mathrm{kg}$ midazolam (Jiangsu Enhua Pharmaceutical Co.), $2 \mathrm{mg} / \mathrm{kg}$ propofol (Fresenius Kabi Austria GmbH), $4 \mu \mathrm{g} / \mathrm{kg}$ fentanyl (Yichang Renfu), and $0.15 \mathrm{mg} / \mathrm{kg}$ cis-atracurium (Shanghai Hengrui Pharmaceutical Co.), followed by intubation and mechanical ventilation. An additional bolus injection of $2 \mu \mathrm{g} / \mathrm{kg}$ fentanyl was injected before incision. Intravenous-inhalation combined anesthesia was performed by intravenous infusion of $2-4 \mathrm{mg} / \mathrm{kg} / \mathrm{h}$ propofol, $0.1 \mathrm{mg} / \mathrm{kg} / \mathrm{h}$ cis-atracurium, and $0.1-0.5 \mu \mathrm{g} / \mathrm{kg} / \mathrm{min}$ remifentanil, and inhalation of $1-2 \%$ sevoflurane (Shanghai Hengrui Pharmaceutical Co.) to maintain a BIS value of 40-60, mean arterial pressure (MAP) within the normal range, and a train of four (TOF) value of 0 . When the drainage tube was ready to be placed, sevoflurane and cis-atracurium were discontinued, and fresh gas flow was adjusted to $10 \mathrm{~L} / \mathrm{min}$. Propofol was modulated to $6-12 \mathrm{mg} / \mathrm{kg} / \mathrm{h}$. At the end of the surgery, all anesthetics were stopped, and $50 \mathrm{mg}$ flurbiprofen and $10 \mathrm{mg}$ azasetron were administered. The patients were then transferred to the PACU for emergence and extubation. If the patients complained of pain [visual analogue scale (VAS) 24], 50-100 $\mu \mathrm{g}$ fentanyl was administered.

\section{Treatments}

As shown in Figure 1, upon admission to the PACU, sputum aspiration was performed, followed by standardized monitoring of hemodynamic data, BIS value, and the TOF ratio. If the hemodynamic fluctuation was $>30 \%$ of the baseline value, or the patient moved while unconscious, $1 \mu \mathrm{g} / \mathrm{kg}$ remifentanil or $1 \mathrm{mg} / \mathrm{kg}$ propofol was administered.
If blood pressure decreased $>30 \%$ of the baseline value during PACU stay, $6 \mathrm{mg}$ ephedrine was administered. Once the TOF ratio reached $0.7,0.04 \mathrm{mg} / \mathrm{kg}$ neostigmine and $0.02 \mathrm{mg} / \mathrm{kg}$ atropine were infused to reverse the effects of the residual muscle relaxant. When the spontaneous tidal volume and RR recovered, the patients were asked to open their eyes every 5 minutes; the tracheal tube was then withdrawn. If the patients still failed to reach the criteria for extubation with the first dosage, they were given a repeated intervention of anesthetics. The anesthetist performing the assessment in the PACU, and the patients were blinded to the injected medication.

\section{Outcomes}

Patient demographic data, anesthetic time (from anesthetic induction to PACU admission), and operative time (from incision to the end of the surgery) were documented.

The primary outcome was the duration of PACU stay, defined as the interval from admission to the PACU to modified Aldrete score $\geq 9$. The secondary outcomes included time to spontaneous breathing recovery (from admission to the PACU to the return of spontaneous breathing) and time to extubation (from admission to the PACU to extubation). The BIS values and hemodynamic data, including systolic blood pressure (SBP), diastolic blood pressure (DBP), and HR were recorded after anesthetic intervention. Times of repeated intervention and rescue administration of vasoactive drugs were recorded. Adverse events, including incidence of hypoxemia $\left(\mathrm{SpO}_{2}<90 \%\right.$ in air-conditioned conditions for $>1$ minute), coughing, 
dizziness, agitation, and nausea and vomiting were also observed during PACU stay. The occurrence and severity of the coughing response during extubation was categorized as mild (1-2 coughs), moderate (3-5 coughs), and severe ( $>5$ coughs) (10). Before the patients were transferred back to the ward, VAS scores were adopted to assess the severity of postoperative pain $(0=$ no pain; $1-3=$ mild pain; $4-6=$ moderate pain; $>7=$ severe pain), and the satisfaction scores of the patients were based on a verbal scale of 1 to $5(1=$ not at all satisfied, $2=$ dissatisfied, $3=$ okay, $4=$ satisfied, $5=$ very satisfied) (11).

\section{Statistical analysis}

All analyses were performed according to the intentionto-treat principle; that is, all randomized patients were analyzed in the groups to which they were originally allocated and were blinded to treatment assignment. A 30\% difference in the duration of PACU stay was considered significant, and the sample size was calculated per group to achieve a power of $90 \%$, with $\alpha=0.05$; the confidence interval of $95 \%$ was 38 . To allow for a $10 \%$ patient dropout rate, the study required 50 patients being enrolled in each group.

Baseline characteristics were summarized by univariate analyses. Continuous variables were summarized and are presented as mean \pm standard deviation or median with 95\% confidence interval, depending on whether they were in accordance with normal distribution. A comparison of continuous variables was performed by using Student's $t$-test for normally distributed variables, and the MannWhitney $U$-test was used for non-normally distributed variables. Qualitative data are presented as frequencies (with percentages), and comparisons among the groups were performed using $\chi^{2}$-test or Wilcoxon rank-sum test, with $\alpha=0.05$.

All tests were two tailed, and a $\mathrm{P}$ value $<0.05$ was considered significant. Analyses were conducted using SPSS version 23.0.

\section{Results}

A total of 200 patients scheduled for laparoscopic staging of endometrial cancer from July 1, 2019 to December 31, 2019 were recruited in the present study. In total, 101 patients were excluded: 11 patients due to conversion to open surgery, 87 patients due to successful withdrawal of tracheal tube without the need for intervention agents, and 3 patients due to bleeding requiring reoperation. Ultimately, a total of 99 patients were enrolled and randomized to the Rem group ( $\mathrm{n}=51)$ or Pro group $(\mathrm{n}=48)$ (Figure 2). Patient demographics and the duration of anesthesia and operation were similar between the two groups (Table 1).

The length of PACU stay was significantly shorter in the Rem group than in the Pro group [ $49.0 \mathrm{~min}$ (46.47-51.06 $\mathrm{min})$ vs. $62.0 \mathrm{~min}(60.75-69.29 \mathrm{~min})$, $\mathrm{P}<0.0001$ ] (Figure 3A). Similarly, the time to spontaneous breathing recovery and time to extubation were significantly less in the Rem group $(23.2 \pm 6.9$ vs. $29.6 \pm 7.1 \mathrm{~min}, \mathrm{P}<0.0001)$ compared to the Pro group $(25.7 \pm 6.5$ vs. $32.3 \pm 7.5 \mathrm{~min}$, $\mathrm{P}<0.0001$ ) (Figure 3B).

The BIS value after anesthetic intervention decreased less in the Rem group than in the Pro group (48.6 \pm 4.4 vs. 32.4 $\pm 5.7, \mathrm{P}<0.0001$ ) (Figure $4 A$ ). The SBP, DBP, and HR dropped in both groups, but were still within the normal range $( \pm 30 \%$ of the baseline values; Rem group vs. Pro group: $105.6 \pm 10.9$ vs. $103.2 \pm 9.9 \mathrm{mmHg}$ in SBP, $\mathrm{P}=0.24 ; 56.0 \pm 9.3$ vs. $53.3 \pm 8.8 \mathrm{mmHg}$ in $\mathrm{DBP}, \mathrm{P}=0.16$; $62.7 \pm 7.8$ vs. $64.0 \pm 9.3 \mathrm{bpm}$ in $\mathrm{HR}, \mathrm{P}=0.51$, respectively) (Figure 4B,C,D). We also found that only four patients in the Pro group and three in the Rem group required ephedrine to elevate blood pressure during extubation $(\mathrm{P}=0.93)$ (Table 2). In addition, 15 patients in the Rem group and 16 in the Pro group required anesthetic intervention twice, whereas three patients in the Rem group and four in the Pro group required this intervention three times $(\mathrm{P}=0.79)$ (Table 2).

During extubation, remifentanil was found to inhibit the degree of coughing response, although no significant difference was observed in the incidence and degree of cough response between the two groups $(\mathrm{P}=0.06)$ (Table 2). Twenty minutes after extubation, eight patients in the Pro group, but only one patient in the Rem group, suffered from hypoxemia $(17 \%$ vs. $2 \%, \mathrm{P}=0.03)$. The incidence of dizziness ( $6 \%$ vs. $13 \%, \mathrm{P}=0.43)$, agitation $(6 \%$ vs. $6 \%$, $\mathrm{P}=1.00)$, and nausea and vomiting $(14 \%$ vs. $4 \%, \mathrm{P}=0.19)$ were similar between the two groups (Rem group vs. Pro group). Only five patients in each group asked for fentanyl rescue, VAS and satisfaction scores were comparable between the two groups $(\mathrm{P}=0.82$ and $\mathrm{P}=0.57$, respectively).

\section{Discussion}

Hospital, professional, and societal costs are increased by delays in admission into the PACU. It is necessary to transfer patients to the PACU for emergence and 


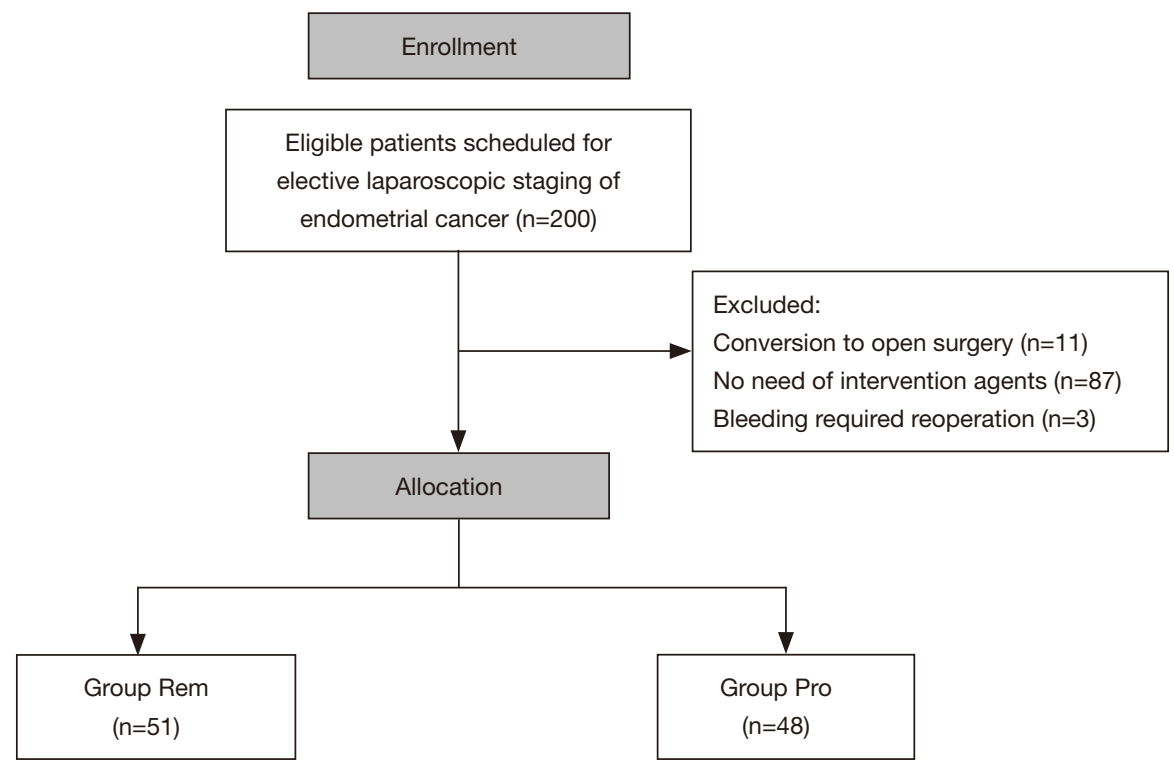

Figure 2 Flow chart depicting the selection of patients for the present study. Patients who were assessed for eligibility and a proportion of them were excluded, as they did not meet the inclusion criteria.

Table 1 Baseline characteristics of the patients $(\mathrm{x} \pm \mathrm{SD}$ or $\mathrm{n}, \%)$

\begin{tabular}{lccc}
\hline Variables & Group Rem $(\mathrm{n}=51)$ & Group Pro $(\mathrm{n}=48)$ & $\mathrm{P}$ \\
\hline Age $(\mathrm{y})$ & $52.6 \pm 10.7$ & $50.27 \pm 11.70$ & 0.30 \\
$\mathrm{BMI}\left(\mathrm{kg} / \mathrm{m}^{2}\right)$ & $23.44 \pm 3.70$ & $24.64 \pm 2.95$ & 0.08 \\
ASA $(\mathrm{I} / \mathrm{II})$ & $43 / 8$ & $43 / 5$ & 0.44 \\
Hypertension & $12(24 \%)$ & $15(31 \%)$ & 0.39 \\
Diabetes & $8(16 \%)$ & $5(10 \%)$ & 0.44 \\
Duration of anesthesia (min) & $208.08 \pm 25.76$ & $215.91 \pm 20.67$ & 0.10 \\
Duration of operation (min) & $192.34 \pm 23.60$ & $198.67 \pm 19.91$ & 0.15 \\
\hline
\end{tabular}

Rem, remifentanil; Pro, propofol; BMI, body mass index; ASA, American Society of Anesthesiologists.

extubation. Therefore, the ability of the PACU to accommodate postoperative patients is closely linked with efficient OR activity. The PACU may become a bottleneck due to its inability to discharge patients as soon as possible, which may subsequently affect the turnover of beds (12). During emergence, sedative administration, short-acting opioid drugs, and other methods have been used in the clinic for smooth extubation. However, these strategies may induce PACU "stacking". Therefore, it is particularly important to determine an appropriate method to enhance the efficiency of the PACU. In the present randomized clinical trial, we found that a bolus injection of remifentanil during emergence can shorten PACU stay, speed up the turnover of beds, and provide a satisfactory condition for tracheal extubation without increasing adverse events.

Remifentanil, a useful analgesic for ICU patients, can provide analgesia-based sedation without the need for propofol (9). For its organ-independent metabolism through non-specific blood and tissue esterases, remifentanil can be hydrolyzed, regardless of the duration of its administration (13), even in those with renal or liver dysfunction (14). In comparison, because it is characterized by a large volume of distribution at a steady state and a relatively long elimination half time, the context-sensitive half-life of propofol after a 90-minute transfusion is nearly 50 minutes in adults (15). Guignard et al. suggested that a 

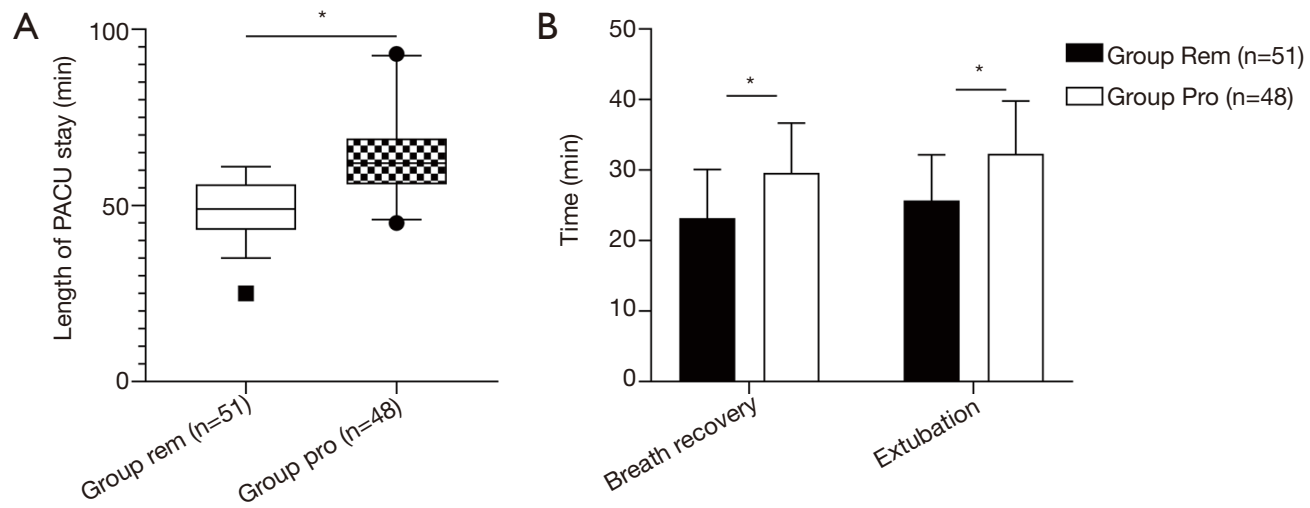

Figure 3 Parameters in PACU stay of the two different groups. Length of PACU stay (A) and was significantly shorter in group Rem, compared with group Pro. The time to spontaneous breath recovery and time to extubation (B) were less in group Rem than those in group Pro. *, $\mathrm{P}<0.001$. The Box and Whisker plot on the left represent range interquartile and the outliers respectively. PACU, post-anesthesia care unit; Rem, remifentanil; Pro, propofol.

A

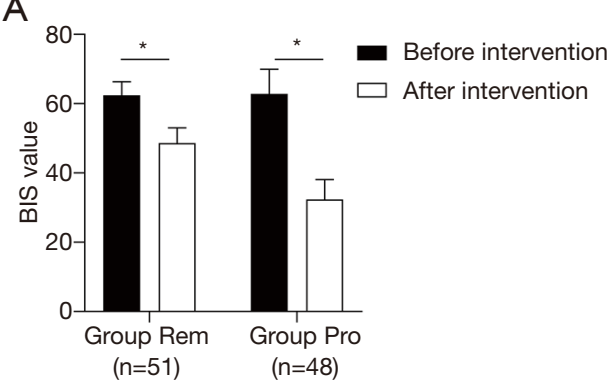

C

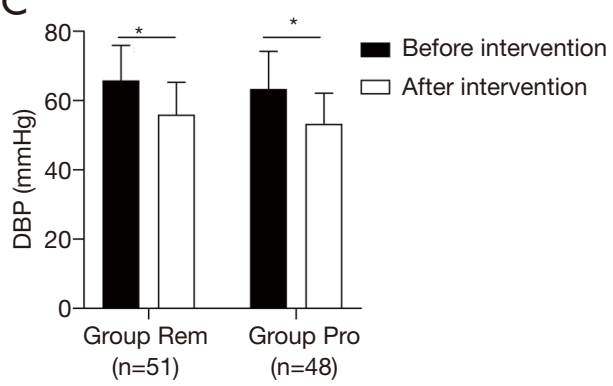

B

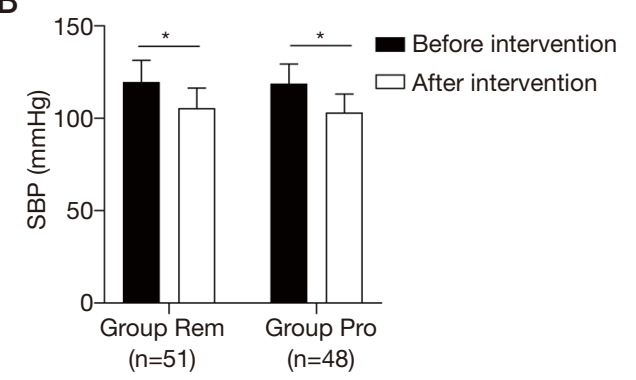

D

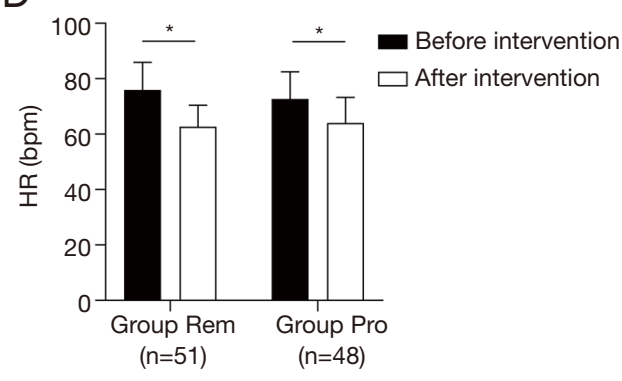

Figure 4 The BIS value and hemodynamic parameters after anesthetic intervention in both groups. The BIS value after anesthetic intervention decreased less in group Rem than that in group Pro (A). The SBP, DBP, and HR dropped in both groups, but still within the normal range ( $\pm 30 \%$ of the baseline values) (B,C,D). * $\mathrm{P}<0.001$. BIS, bispectral index; Rem, remifentanil; Pro, propofol; SBP, systolic blood pressure; DBP, diastolic blood pressure; HR, heart rate.

bolus injection of remifentanil does not cause a significant decrease in the BIS value, even in deep anesthesia (16). Jung et al. also reported that remifentanil could effectively alleviate propofol-induced burst inhibition without affecting BIS values, even in the absence of noxious stimuli and muscle relaxants (17). These results are in accordance with those of the present study, indicating that after a long duration of laparoscopic surgery under propofol-based anesthesia, an additional bolus injection of propofol during emergence might easily induce a relative deep hypnosis due to a significantly decreased BIS value. In our study, we found that a bolus injection of $1 \mu \mathrm{g} / \mathrm{kg}$ remifentanil had a 
Table 2 Occurrence of recovery variables, adverse events, VAS score and satisfaction score in patients in PACU

\begin{tabular}{|c|c|c|c|}
\hline Variables & Group Rem ( $n=51)$ & Group Pro $(n=48)$ & $P$ \\
\hline $\begin{array}{l}\text { Additional bolus of intervention anesthetics } \\
\text { ( } 2 \text { times } / 3 \text { times) }\end{array}$ & $15 / 3$ & $16 / 4$ & 0.79 \\
\hline Cough response during extubation $(1 / 2 / 3 / 4 / 5)$ & $19 / 23 / 9 / 0 / 0$ & $13 / 17 / 18 / 0 / 0$ & 0.06 \\
\hline Agitation & $3(6 \%)$ & $3(6 \%)$ & 1.00 \\
\hline Nausea or vomiting & $7(14 \%)$ & $2(4 \%)$ & 0.19 \\
\hline VAS (no pain/mild/moderate/severe) & $17 / 29 / 5 / 0$ & $15 / 28 / 5 / 0$ & 0.82 \\
\hline
\end{tabular}

*, P<0.05. PACU, post-anesthesia care unit; Rem, remifentanil; Pro, propofol; VAS, verbal analog scale. Cough response score: $1=$ no cough and muscle rigidity; $2=$ mild cough; $3=$ moderate cough; $4=$ moderate cough or muscle rigidity; $5=$ agitation, cannot be extubated. VAS score: $0=$ no pain; $1-3=$ mild pain; $4-6=$ moderate pain; $>7=$ severe pain. The satisfaction scores of the patients: $1=$ for not at all satisfied; $2=$ dissatisfied; $3=$ okay; $4=$ satisfied; $5=$ very satisfied.

slight impact on BIS value, and most cases had a BIS value $>40$, which might be associated with earlier extubation, resulting in shorter PACU stay.

As our results showed, most of the patients in the Rem group were fully awake when extubated and recovered thoroughly after extubation without dizziness, hypoxemia, and drowsiness. However, respiratory depression can occur with propofol. Although a bolus injection of remifentanil may also induce transient and mild respiratory depression, it is easily treated by increasing oxygen concentration and encouraging patients to breathe (18). Compared with propofol, remifentanil can provide moderate sedation and analgesia without causing deep anesthesia. Furthermore, propofol is metabolized depending on the state of renal and liver function; its metabolism varies according to sex, age, physical condition, and content of body fat due to adipopexis (19); therefore, it is less controllable and may lead to delays in extubation, subsequently increasing PACU stay.

It is well recognized that the administration of $2-2.5 \mathrm{mg} / \mathrm{kg}$ propofol can lead to a $25-40 \%$ decrease in SBP and cardiac output (20). However, the dosage of propofol, which could provide effective sedation and hypnosis for tolerance endotracheal tube and have little effect on hemodynamic responses, is far below the above usage. Remifentanil, a potent synthetic selective $\mu$-opioid receptor agonist with a rapid onset and short duration of action, can provide sedation and analgesia during the placement of the endotracheal tube, and can cause blunt reflex responses (21). Lee et al. reported that the infusion of $1 \mu \mathrm{g} / \mathrm{kg}$ remifentanil, which is in accordance with ours, could lead to a decrease in blood pressure and HR in an acceptable safely range (22). In our study, the prophylactic administration of either $1 \mu \mathrm{g} / \mathrm{kg}$ remifentanil or $1 \mathrm{mg} / \mathrm{kg}$ propofol upon admission to the PACU inhibited the hemodynamic response, with some patients requiring ephedrine rescue in both groups due to the fluctuation still being within the normal range; however, this was rare.

Previous studies have demonstrated that remifentanil has an antitussive effect on emergence from anesthesia, and that remifentanil could effectively and safely suppress the coughing response by inhibiting airway reflex and attenuating the stimulus of the tracheal tube $(23,24)$. This finding is in agreement with that of the present study, and demonstrates that both remifentanil and propofol could effectively prevent a coughing response during emergence from general anesthesia. Simultaneously, we also found that the patients treated with remifentanil did not experience an increased incidence of adverse events, such as agitation, nausea, and vomiting.

The present study has some limitations. First, we recruited only female patients scheduled for laparoscopic staging of endometrial cancer; the effect of remifentanil on the duration of PACU stay for other patient populations needs to be further investigated. Second, the remifentanil dosage used in our study was based on the experience of our department. To ensure that extubation is performed 
safely and as early as possibly, without causing PACU delay, further exploration of appropriate remifentanil dosages is necessary. Third, we could not confirm whether remifentanil used in emergence has an effect on long-term complications, including opioid-induced hyperalgesia, as we did not follow-up these patients after they were discharged from hospital.

In conclusion, during emergence, a bolus injection of remifentanil can effectively shorten the length of PACU stay without increasing adverse events in the periextubation period. Owing to its minor impact on BIS value and hemodynamic parameters, remifentanil can provide smooth extubation, early emergence, and efficient PACU throughput.

\section{Acknowledgments}

We thank all the survey respondents who participated in the study. We also would like to thank AME Editing Service (http://editing.amegroups.cn/\#editing) for English language editing.

Funding: None.

\section{Footnote}

Reporting Checklist: The authors have completed the CONSORT reporting checklist. Available at http://dx.doi. org/10.21037/apm-20-1146

Data Sharing Statement: Available at http://dx.doi. org/10.21037/apm-20-1146

Peer Review File: Available at http://dx.doi.org/10.21037/ apm-20-1146

Conflicts of Interest: All authors have completed the ICMJE uniform disclosure form (available at http://dx.doi. org/10.21037/apm-20-1146). The authors have no conflicts of interest to declare.

Ethical Statement: The authors are accountable for all aspects of the work in ensuring that questions related to the accuracy or integrity of any part of the work are appropriately investigated and resolved. The study was conducted in accordance with the Declaration of Helsinki (as revised in 2013). This study was approved by the Institutional Ethics Committee of the $1^{\text {st }}$ Affiliated Hospital of Nanjing Medical University (Nanjing, China) (No.:
2019-SR-225) and was registered in the Chinese clinical trial (No.: ChiCTR1900025773). Written informed consent was obtained from all patients or their legal representative prior to enrollment in the study.

Open Access Statement: This is an Open Access article distributed in accordance with the Creative Commons Attribution-NonCommercial-NoDerivs 4.0 International License (CC BY-NC-ND 4.0), which permits the noncommercial replication and distribution of the article with the strict proviso that no changes or edits are made and the original work is properly cited (including links to both the formal publication through the relevant DOI and the license). See: https://creativecommons.org/licenses/by-nc-nd/4.0/.

\section{References}

1. Parikh BK, Shah VR, Modi PR, et al. Anaesthesia for laparoscopic kidney transplantation: Influence of Trendelenburg position and $\mathrm{CO} 2$ pneumoperitoneum on cardiovascular, respiratory and renal function. Indian J Anaesth 2013;57:253-8.

2. Cheng YC, Li Y, Xu CT, et al. Effects of propofol versus urapidil on perioperative hemodynamics and intraocular pressure during anesthesia and extubation in ophthalmic patients. Int J Ophthalmol 2011;4:170-4.

3. Miao B, Storer RH, Tonkay GL. A Sample-gradientbased Algorithm for a Multiple-OR and PACU Surgery Scheduling Problem. IISE Trans 2016;49:367-80.

4. $\mathrm{Lu} \mathrm{CH}, \mathrm{Wu} \mathrm{ZF}$, Lin BF, et al. Faster extubation time with more stable hemodynamics during extubation and shorter total surgical suite time after propofol-based total intravenous anesthesia compared with desflurane anesthesia in lengthy lumbar spine surgery. J Neurosurg Spine 2016;24:268-74.

5. Takahashi H, Maruo Y, Mori A, et al. Effect of D256N and $\mathrm{Y} 483 \mathrm{D}$ on propofol glucuronidation by human uridine 5'-diphosphate glucuronosyltransferase (UGT1A9). Basic Clin Pharmacol Toxicol 2008;103:131-6.

6. Loryan I, Lindqvist M, Johansson I, et al. Influence of sex on propofol metabolism, a pilot study: implications for propofol anesthesia. Eur J Clin Pharmacol 2012;68:397-406.

7. Dinis-Oliveira RJ. Metabolic Profiles of Propofol and Fospropofol: Clinical and Forensic Interpretative Aspects. Biomed Res Int 2018;2018:6852857.

8. Cabrini L, Baiardo Redaelli M, Ball L, et al. Awake Fiberoptic Intubation Protocols in the Operating Room 
for Anticipated Difficult Airway: A Systematic Review and Meta-analysis of Randomized Controlled Trials. Anesth Analg 2019;128:971-80.

9. Kim SY, Yang SY, Na SW, et al. Low-dose remifentanil infusion during ventilator weaning and tracheal extubation in postoperative intensive care unit patients sedated with propofol-remifentanil: a randomised clinical trial. Anaesth Intensive Care 2012;40:656-62.

10. Marashi SM, Hassan Nikkhouei R, Movafegh A, et al. Comparison of the Effects of Magnesium Sulfate and Remifentanil on Hemodynamic Responses During Tracheal Extubation After Laparotomy: A Randomized Double-blinded Trial. Anesth Pain Med 2015;5:e25276.

11. Wu J, Lu Y, Cao X. Different effects of oxycodone and remifentanil in patients undergoing ultrasound-guided percutaneous radiofrequency ablation of hepatic cancer: a randomized trial. Drug Des Devel Ther 2019;13:365-72.

12. Weissman C, Scemama J, Weiss YG. The ratio of PACU length-of-stay to surgical duration: Practical observations. Acta Anaesthesiol Scand 2019;63:1143-51.

13. Beers R, Camporesi E. Remifentanil update: clinical science and utility. CNS drugs 2004;18:1085-104.

14. Muellejans B, López A, Cross MH, et al. Remifentanil versus fentanyl for analgesia based sedation to provide patient comfort in the intensive care unit: a randomized, double-blind controlled trial [ISRCTN43755713]. Crit Care 2004;8:R1-R11.

15. Hachenberg T. Perioperative management with shortacting intravenous anesthetics. Anaesthesiol Reanim 2000;25:144-50.

16. Guignard B, Menigaux C, Dupont X, et al. The effect of remifentanil on the bispectral index change and hemodynamic responses after orotracheal intubation. Anesth Analg 2000;90:161-7.

Cite this article as: Zhu LJ, Zhang SB, Jiang XH, Ni Y. Remifentanil injected during analepsia shortens length of postanesthesia care unit stay in patients undergoing laparoscopic surgery for endometrial cancer: a randomized controlled trial. Ann Palliat Med 2021;10(2):1207-1215. doi: 10.21037/apm-20-1146
17. Jung D, Yang S, Lee MS, et al. Remifentanil Alleviates Propofol-Induced Burst Suppression without Affecting Bispectral Index in Female Patients: A Randomized Controlled Trial. J Clin Med 2019;8:1186.

18. Egan TD, Kern SE, Muir KT, et al. Remifentanil by bolus injection: a safety, pharmacokinetic, pharmacodynamic, and age effect investigation in human volunteers. Br J Anaesth 2004;92:335-43.

19. Siampalioti A, Karavias D, Zotou A, et al. Anesthesia management for the super obese: is sevoflurane superior to propofol as a sole anesthetic agent? A double-blind randomized controlled trial. Eur Rev Med Pharmacol Sci 2015;19:2493-500.

20. Miller R, Eriksson L, Fleisher L, et al. Miller's anesthesia. 8th edition. Philadelphia: Elsevier, 2015.

21. Wu YX, Chen H, Zhou JX. Short-term use of remifentanil during endotracheal extubation for prophylactic analgesia in neurosurgical patients after craniotomy (SURE after Craniotomy Study): a study protocol and statistical analysis plan for a randomised controlled trial. BMJ Open 2014;4:e005635.

22. Lee SK, Jeong MA, Sung JM, et al. Effect of remifentanil infusion on the hemodynamic response during induction of anesthesia in hypertensive and normotensive patients: a prospective observational study. J Int Med Res 2019;47:6254-67.

23. Choi SH, Min KT, Lee JR, et al. Determination of EC95 of remifentanil for smooth emergence from propofol anesthesia in patients undergoing transsphenoidal surgery. J Neurosurg Anesthesiol 2015;27:160-6.

24. Aouad MT, Al-Alami AA, Nasr VG, et al. The effect of low-dose remifentanil on responses to the endotracheal tube during emergence from general anesthesia. Anesth Analg 2009;108:1157-60. 